\title{
Reduced Graphene Oxide Reinforced 7075 Al Matrix Composites: Powder Synthesis and Mechanical Properties
}

\author{
Youhong Sun ${ }^{1,2}$, Chi Zhang ${ }^{1,2}$, Baochang Liu ${ }^{1,2, *}$, Qingnan Meng ${ }^{1,2, *}$, Shaoming Ma ${ }^{1,2}$ \\ and Wenhao Dai ${ }^{1}$ \\ 1 School of Construction Engineering, Jilin University, Changchun 130026, China; syh@jlu.edu.cn (Y.S.); \\ zhangchi15@mails.jlu.edu.cn (C.Z.); masm14@mails.jlu.edu.cn (S.M.); daiwh2414@mails.jlu.edu.cn (W.D.) \\ 2 Key Laboratory of Drilling and Exploitation Technology in Complex Conditions, \\ Ministry of Land and Resources, No. 938 Ximinzhu Street, Changchun 130026, China \\ * Correspondence: liubc@jlu.edu.cn (B.L.); qingnanmeng@jlu.edu.cn (Q.M.); \\ Tel./Fax: +86-431-8850-2357 (B.L. \& Q.M.)
}

Received: 25 September 2017; Accepted: 7 November 2017; Published: 13 November 2017

\begin{abstract}
Reduced graphene oxide (rGO) reinforced $7075 \mathrm{Al}$ matrix composites were fabricated by electrostatic self-assembly and powder metallurgy. $7075 \mathrm{Al}$ powders were surface modified by introducing a cetyl trimethyl ammonium bromide (CTAB) membrane on the surface, which was able to form a strong bonding with graphene oxide (GO) through electrostatic interaction. During the vacuum sintering process, $\mathrm{CTAB}$ was effectively removed and $\mathrm{GO}$ was thermally reduced into rGO. Morphologies of GO nanosheets, GO/7075 Al powders, microstructures, and tensile fractographs of the composites were observed. The effect of rGO content on mechanical properties of $\mathrm{rGO} / 7075 \mathrm{Al}$ composites was investigated. The results show that a good bonding between $\mathrm{rGO}$ and matrix is achieved. With the rGO content increasing, the hardness increases gradually, while the ultimate tensile strength and yield strength initially increase and later decrease. The improvement in strength of $\mathrm{rGO} / 7075 \mathrm{Al}$ composites was attributed to stress transfer and dislocation strengthening. With $\mathrm{rGO}$ content reaching $0.50 \mathrm{wt} \%$, the excessive addition of rGO gave rise to a weakening in the enhancement of the tensile properties due to the increasing amounts of brittle $\mathrm{Al}_{4} \mathrm{C}_{3}$ and cracks.
\end{abstract}

Keywords: metal matrix composites; $7075 \mathrm{Al}$ alloy; reduced graphene oxide; mechanical properties; strengthening mechanism

\section{Introduction}

Today, aluminum matrix composites (AMCs) reinforced with nanoparticles, fibers, or whiskers are in high demand due to their attractive characteristics, such as low density combined with high strength, large matrix selectable range, various production processes, and considerable improvement in mechanical properties after heat treatment [1,2]. Due to these desirable properties, AMCs are widely applied as structural materials in many industries, such as automobiles, aerospace, as well as drill pipe material used in extra-deep oil drilling [3-6]. Among aluminum alloys, 7000-series aluminum alloys possess the highest strength-to-weight ratio, which makes them an attractive candidate for reinforcement by a second phase to further improve their properties [7-9].

As the perfect layer structure of two-dimensional (2D) sp2-hybridized carbon atoms, graphene has been extensively investigated in recent years due to its outstanding properties, such as high Young's modulus, high fracture strength, and excellent thermal conductivity [10-14]. Due to these excellent mechanical properties and high specific surface area, graphene is expected to be an ideal reinforcement phase interacting with aluminum matrix, even in a small concentration. However, 
the research on AMCs reinforced with graphene is still in its infancy because the dispersion method, preparation technology, and harmful interface reaction have become the main problems that restrict its development [15].

Powder metallurgy is widely used for the preparation of AMCs due to its low processing temperature, which is beneficial for mitigating a harmful interface reaction. The uniform dispersion of graphene has been regarded as the most important factor in order to achieve high strength. Ball milling (BM) is normally carried out for the dispersion of graphene in aluminum. Wang et al. [16] have fabricated aluminum composites reinforced with graphene nanosheets (GNS/Al composite) through a feasible methodology based on flake powder metallurgy, and found that $0.30 \mathrm{wt} \%$ GNSs give rise to $62 \%$ enhancement over pure Al. However, Bartolucci et al. [17] have investigated the mechanical properties of $0.1 \mathrm{wt} \%$ GNSs / Al composite through BM followed by hot isostatic pressing and hot extrusion, and obtained a remarkable decrease in tensile strength and elongation for $0.1 \mathrm{wt} \% \mathrm{GNS} / \mathrm{Al}$ composite compared with pure Al. In addition, BM produces a great deal of heat that can easily cause an explosion.

In this work, graphene oxide (GO) nanosheets, rather than graphene, are used as a raw material, because many hydroxyl and epoxy groups existing on the surface of GO make it much easier to realize the uniform adsorption of GO on $7075 \mathrm{Al}$ powders free of BM via an electrostatic self-assembly [18]. The effect of electrostatic self-assembly process on achieving the uniform adsorption of GO on $7075 \mathrm{Al}$ powders is investigated in detail. In this process, CTAB is used to introduce a cationic membrane on the surface of $7075 \mathrm{Al}$ powders, which ensures a strong bonding between CTAB-modified $7075 \mathrm{Al}$ powder and GO with a negative charge. The in situ removal of CTAB and the reduction of GO are achieved during the sintering process. Furthermore, the influences of reduced graphene (rGO) on hardness and tensile properties of the composites are investigated. The strengthening mechanisms of rGO reinforcing $7075 \mathrm{Al}$ are elaboratedd.

\section{Experimental Procedures}

\subsection{Research Materials}

Graphite oxide having particle size of $5 \mu \mathrm{m}$ with 99\% purity was provided by Hengqiu Graphene Technology Co. Ltd., Suzhou, China. CTAB obtained from Shandong West Asia Chemical Industry Co. Ltd., Jinan, China was in powder form with an ignited residue content less than $0.1 \mathrm{wt} \%$. As a starting material, spherical $7075 \mathrm{Al}$ powders (99\% purity, $\sim 9 \mu \mathrm{m})$ were supplied by Chaowei Nanotechnology Co. Ltd., Shanghai, China. The nominal composition of the as-received $7075 \mathrm{Al}$ powder in this investigation is listed in Table 1.

Table 1. The chemical composition of the as-received $7075 \mathrm{Al}$ powder.

\begin{tabular}{ccccccccc}
\hline Elements & Zn & Mg & Cu & Fe & Si & Mn & Others & Al \\
\hline (wt $\%)$ & 5.720 & 2.310 & 1.560 & 0.092 & 0.087 & 0.080 & 0.050 & bal. \\
\hline
\end{tabular}

\subsection{Composites Preparation}

Figure 1 elaborates the fabrication procedure of the rGO/7075 Al composites used in this investigation. Four principle steps are involved in the fabrication process:

(1) Preparation of GO aqueous dispersion: To strip the as-received graphite oxides into GO nanaosheets with several-layers structure, the graphite oxide was added into deionized water and then ultrasonicated for $2 \mathrm{~h}$ to obtain a brown dispersion with no residual sediment. A $1 \mathrm{mg} / \mathrm{mL}$ GO aqueous dispersion was finally prepared. Figure 2 displays an AFM image of GO nanosheets obtained from the GO aqueous dispersion. As can be seen, the thickness of the GO nanosheets was $\sim 5 \mathrm{~nm}$. Considering the thickness of monolayer GO nanosheets was $\sim 1 \mathrm{~nm}$ due to the 
attachment of oxygen functionalities [19], the GO nanosheets used in this investigation were no more than five layers.

(2) Modifying $7075 \mathrm{Al}$ powders with CTAB: $50 \mathrm{~g} 7075 \mathrm{Al}$ powders and $300 \mathrm{~mL}$ CTAB aqueous solution ( $0.8 \mathrm{wt} \%$ ) were magnetically stirred for $2 \mathrm{~h}$, filtered, and then rinsed with deionized water to obtain the CTAB-modified $7075 \mathrm{Al}$ powders.

(3) Adsorption of $\mathrm{GO}$ onto the $7075 \mathrm{Al}$ powders: A powder slurry was prepared through adding CTAB-modified $7075 \mathrm{Al}$ powders ( $\sim 50 \mathrm{~g})$ into deionized water. The GO aqueous dispersion was added drop by drop. The mixed slurry was magnetically stirred until the color changed to transparent, and was then filtered and rinsed to obtain the composite powders. The composite powders were finally vacuum dried at $70{ }^{\circ} \mathrm{C}$ for $8 \mathrm{~h}$.

(4) $\mathrm{CTAB}$ removal and $\mathrm{rGO} / 7075 \mathrm{Al}$ composites fabrication. No particular heating treatment was used to remove the $\mathrm{CTAB}$ and reduce the $\mathrm{GO}$, because the sintering temperature $\left(560^{\circ} \mathrm{C}\right)$ was high enough to achieve the purpose. The green billets ( $30 \mathrm{~mm}$ in diameter and $40 \mathrm{~mm}$ in height) were prepared through compacting the composite powders under $140 \mathrm{MPa}$ at room temperature. Subsequently, the green billets were heated in a vacuum furnace at $560^{\circ} \mathrm{C}$ for $2 \mathrm{~h}$, followed by hot pressing under $70 \mathrm{MPa}$ for $10 \mathrm{~min}$ to ensure the density. After that, slabs with cross-sections $12 \mathrm{~mm}$ in width and $4 \mathrm{~mm}$ in thickness were obtained by hot extrusion at $450^{\circ} \mathrm{C}$. The extrusion ratio and ram speed used in present study were 14.7 and $1 \mathrm{~mm} / \mathrm{s}$, respectively. Subsequently, the slabs were solution-treated in a resistance furnace at $470{ }^{\circ} \mathrm{C}$ for $2 \mathrm{~h}$, followed by water quenched, and then aged at $120^{\circ} \mathrm{C}$ for $24 \mathrm{~h}$. The contents of rGO in the composites were 0.15 , 0.30 , and $0.50 \mathrm{wt} \%$, respectively. For comparison, a $7075 \mathrm{Al}$ sample was also prepared using the same method without adding GO.

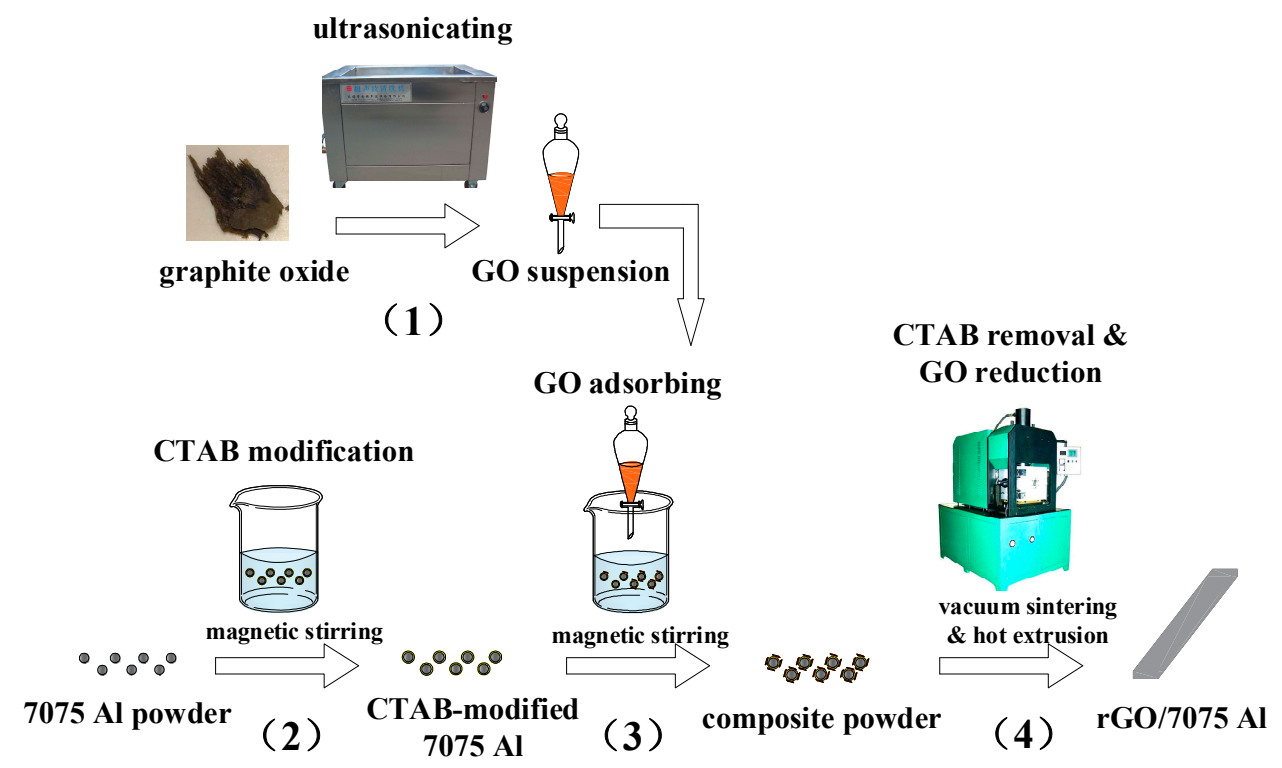

Figure 1. Fabrication procedures for $\mathrm{rGO} / 7075 \mathrm{Al}$ composites.
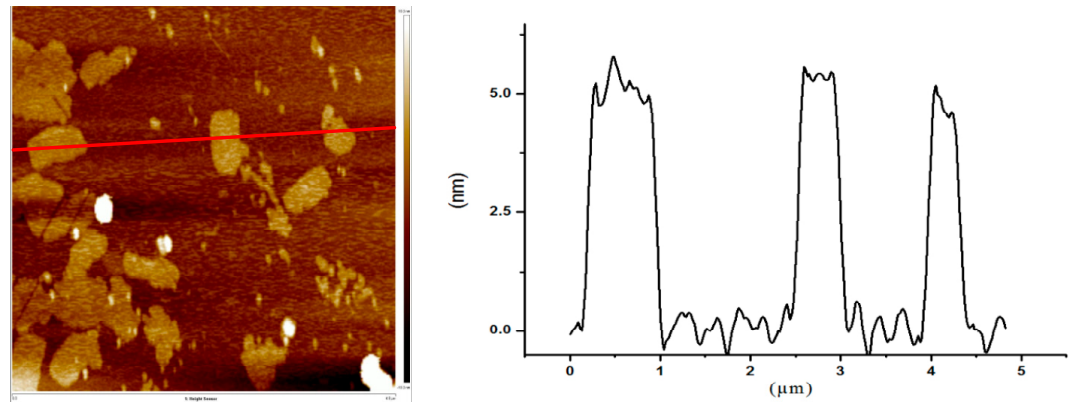

Figure 2. AFM image of the GO nanosheets and depth profile of the line on the GO nanosheets. 


\subsection{Mechanical Properties and Density Measurements}

The specimens were prepared in accordance with ASTM Standard E-8/E8M-09 [20] parallel to the extrusion direction with a $10 \mathrm{~mm}$ gauge length. The tensile test was performed after polishing the samples in air at room temperature using an electronic universal test machine (DDL 100, CIMACH, Changchun, China) operated at a constant crosshead speed with an initial strain rate of $5 \times 10^{-4} \mathrm{~s}^{-1}$. At least three samples for each composite were measured to ensure the accuracy. The hardness of the composites and $7075 \mathrm{Al}$ samples were tested by a microhardness tester (1600-5122VD Microment 5104, Buehler Ltd., Chicago, IL, USA) under an applied load of $100 \mathrm{~g}$ for $15 \mathrm{~s}$. At least seven measurements were performed for each condition to ensure the accuracy of the results. The relative density of the as extruded composites and $7075 \mathrm{Al}$ samples was measured by Archimedes' principle.

\subsection{Microstructure Characterizations}

The microstructures were characterized by a scanning electron microscopy (SEM; S-4800, Hitachi Ltd., Tokyo, Japan). Fourier transform infrared spectroscopy (FTIR; Thermal Scientific Nicolet iS10, Nicolet Ltd., Madison, WI, USA) was used to identify functional groups in GO, CTAB-modified $7075 \mathrm{Al}$ powders, and composite powders. Thermal analysis was carried out using a simultaneous thermal analyzer (STA 499C, Netzsch Ltd., Bavaria, Germany) to analyze the thermal reduction of $\mathrm{GO}$ and $\mathrm{CTAB}$ removal during sintering process. The microstructures of $\mathrm{rGO} / 7075 \mathrm{Al}$ composites were characterized by optical microscopy (OM; Carl Zeiss-Axio Imager A2m, Gottingen, Germany) and transmission electron microscopy (TEM; JEOL-2000EX, Tokyo, Japan). The phase constituents of rGO/7075 Al composites were identified by X-ray diffraction (XRD; D/Max 2500PC, Rigaku Ltd., Tokyo, Japan) using $\mathrm{Cu} \mathrm{K} \alpha$ radiation in step mode from $20^{\circ}$ to $80^{\circ}$ with a scanning speed of $5^{\circ} / \mathrm{min}$.

\section{Results}

\subsection{Improvement in Adsorption Uniformity of GOs by CTAB Modification}

The significant effect of $\mathrm{CTAB}$ on improving the dispersion uniformity of $\mathrm{GO}$ can be proven by comparing the mixture of $\mathrm{GO}$ and $7075 \mathrm{Al}$ with and without CTAB modification. Figure 3 shows the mixture of the GO suspension with the unmodified $7075 \mathrm{Al}$ and the CTAB-modified $7075 \mathrm{Al}$ slurry after magnetic stirring. For the mixture of $\mathrm{GO}$ with unmodified $7075 \mathrm{Al}$, the upper layer of the mixture remains brown, indicating that most of the GO was not absorbed onto the $7075 \mathrm{Al}$ surface and was still in the suspension. Some brown flocs lie on the surface of unmodified $7075 \mathrm{Al}$ slurry, indicating the agglomeration of GO. By contrast, the upper layer of the GO and CTAB-modified 7075 $\mathrm{Al}$ mixture is nearly transparent, suggesting that most of the GO in the mixture was absorbed onto the $7075 \mathrm{Al}$ surface.

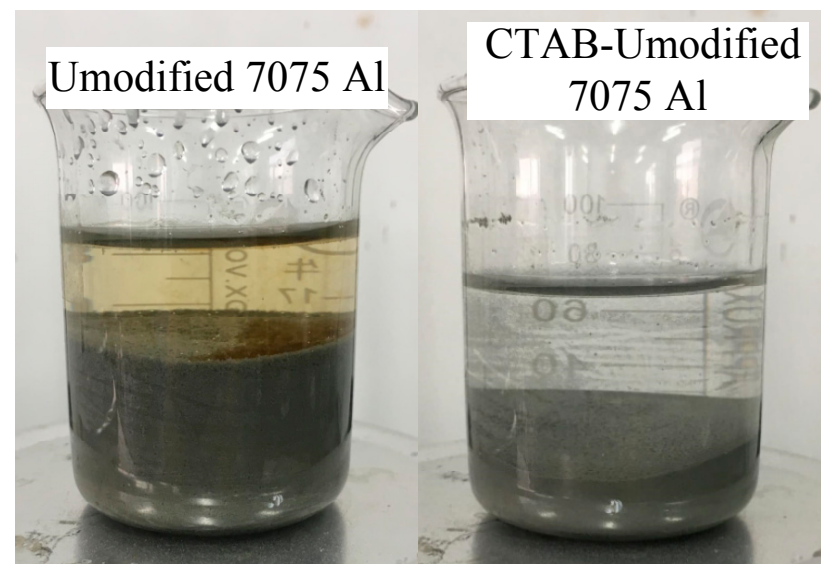

Figure 3. The image of mixture after $7075 \mathrm{Al}$ powders absorbing GO. 
The FTIR spectrum displays the difference of CTAB-modified 7075 Al powder and unmodified $7075 \mathrm{Al}$ powder in terms of surface structure. As shown in Figure 4, the FTIR spectrum of the CTAB-modified $7075 \mathrm{Al}$ powder shows many additional bands compared to that of unmodified $7075 \mathrm{Al}$ powder. The band at $1000 \mathrm{~cm}^{-1}$ is caused by the C-N stretch vibration, a characteristic of CTAB. The band at $1471 \mathrm{~cm}^{-1}$ conveys the message that $\mathrm{CTA}^{+}$cations are in a liquid-like molecular environment where the alkyl chain of $\mathrm{CTA}^{+}$rotates freely around its long axis [21]. The strong absorption bands at $2918 \mathrm{~cm}^{-1}$ and $2849 \mathrm{~cm}^{-1}$ correspond to the C-H symmetrical and asymmetrical stretch vibrations of methyl and methylene, respectively [22]. The FTIR analysis confirms that the $7075 \mathrm{Al}$ surface was coated with the CTAB membrane.

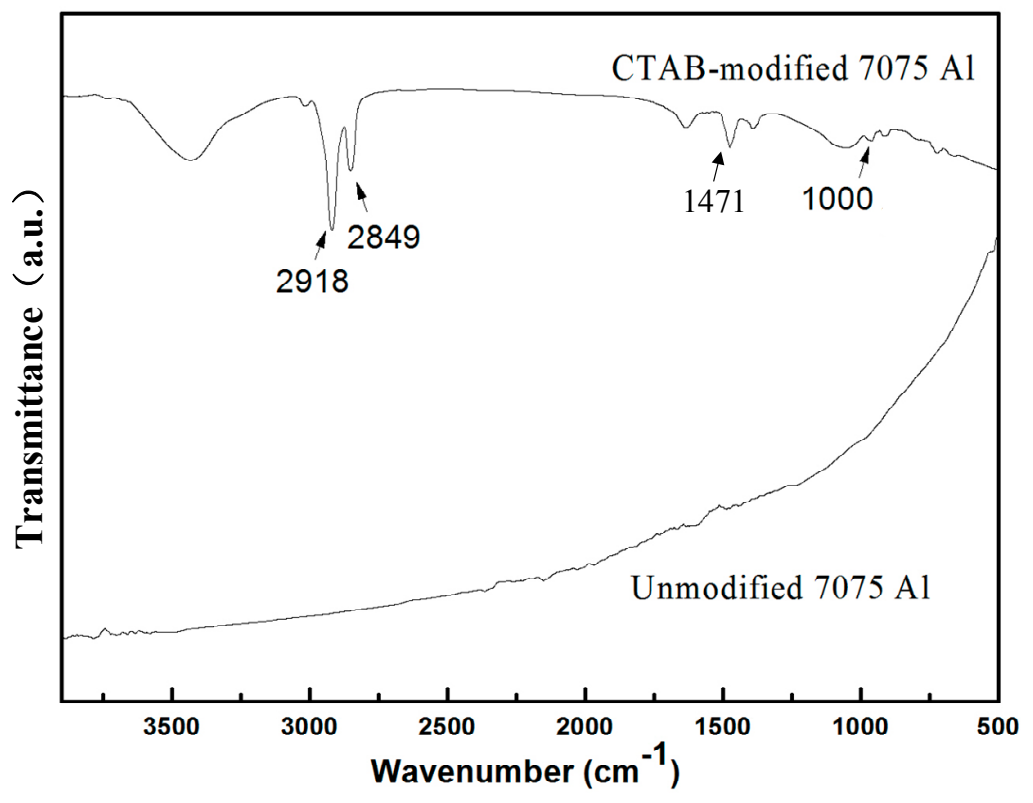

Figure 4. FTIR spectrum of unmodified and CTAB-modified $7075 \mathrm{Al}$ powders.

Typical SEM images of the composite powders are given in Figure 5. For the unmodified $7075 \mathrm{Al}$ powders (Figure 5a), a large area is observed with no adsorption of GO. On the other hand, the severe GO clustering is found on the edge of the powder, indicating an unacceptable dispersion uniformity of GO without CTAB modification. Figure 5b shows the uniform adsorption achieved by CTAB-modified $7075 \mathrm{Al}$ powders. It can be seen that many wrinkles are distributed on the surface of $7075 \mathrm{Al}$ powder and many wrappings of GO are found dispersed at the edge, and no obvious agglomeration of the GO is observed between the particles, indicating a uniform dispersion of GO on the $7075 \mathrm{Al}$ surface.

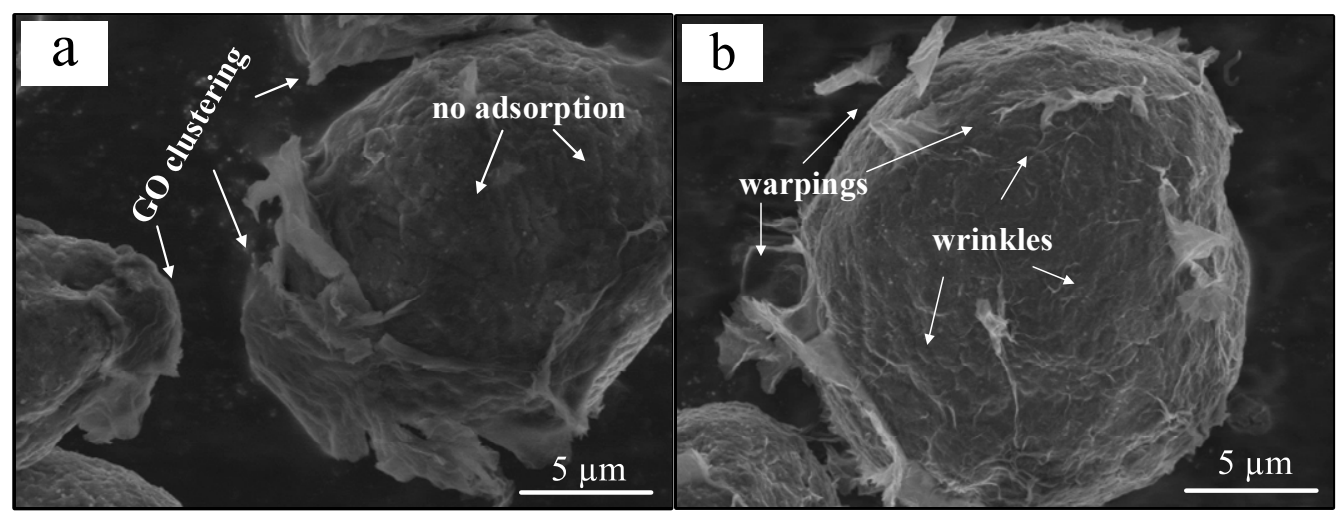

Figure 5. The SEM images of the composite powders: (a) GO clustering in unmodified $7075 \mathrm{Al}$ powders; and (b) uniform adsorption of GO achieved by CTAB modification. 


\subsection{Removal of CTAB and Thermal Reduction of GO during Sintering Process}

In order to study the CTAB removal and the GO reduction during sintering process, TGA was used to analyze the thermal stability of $\mathrm{CTAB}$ and $\mathrm{GO}$ up to $560^{\circ} \mathrm{C}$, with a heating rate of $10^{\circ} \mathrm{C} / \mathrm{min}$. As shown in Figure $6 \mathrm{a}, \mathrm{CTAB}$ shows little mass loss before $200^{\circ} \mathrm{C}$, revealing a favorable thermal stability of $\mathrm{CTAB}$ at low temperature. The curve displays a significant mass loss at $\sim 90 \%$ from $200{ }^{\circ} \mathrm{C}$ to $350{ }^{\circ} \mathrm{C}$, attributed to the $\mathrm{CTAB}$ pyrolysis. In the last stage, the curve displays a stable mass remaining at $\sim 10 \%$, indicating the end of CTAB pyrolysis. The remaining mass could be the residual carbon. The mass remaining curve of GO presented in Figure $6 \mathrm{~b}$ also displays three discrete stages. Firstly, a slight mass loss $(\sim 10 \%)$ occurs up to $150^{\circ} \mathrm{C}$. In the second stage, an additional significant mass loss $(\sim 32 \%)$ occurs up to $260{ }^{\circ} \mathrm{C}$. Finally, an $8 \%$ mass loss can be observed up to $560{ }^{\circ} \mathrm{C}$.
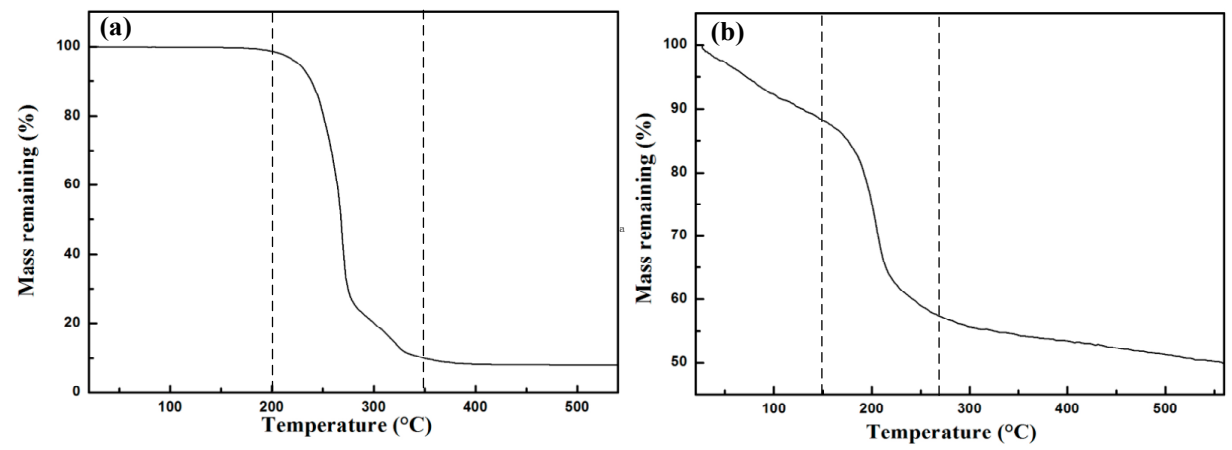

Figure 6. Thermogravimetric analysis (TGA) of (a) CTAB and (b) GO from $20{ }^{\circ} \mathrm{C}$ to $560{ }^{\circ} \mathrm{C}$ at the heating speed of $10^{\circ} \mathrm{C} / \mathrm{min}$.

The XRD patterns (Figure 7a) show the difference for composite powders before and after vacuum heating. For the composite powders before heating, apart from the four peaks corresponding to $\mathrm{Al}$ (PDF\#65-2869), three peaks corresponding to CTAB in the composite powder are observed at $21.48^{\circ}, 22.51^{\circ}$, and $24.51^{\circ}$ (PDF\#48-2454). Meanwhile, no obvious peak corresponding to GO is observed, which might result from the low content of GO. For the composite powders after heating, only four Al peaks are observed from the XRD pattern, while CTAB peaks have all vanished, revealing the removal of CTAB. Figure $7 \mathrm{~b}$ also shows a typical FTIR spectra of GO before and after heating. For the FTIR spectra of GO before heating, there is a broad and intense band of $\mathrm{O}-\mathrm{H}$ stretching vibration at $3418 \mathrm{~cm}^{-1}$, as well as the bands of $\mathrm{C}=\mathrm{O}, \mathrm{C}-\mathrm{O}-\mathrm{C}$ stretching vibration at $1722 \mathrm{~cm}^{-1}$ and $1052 \mathrm{~cm}^{-1}$. There is also a band of O-H deformation vibration at $1395 \mathrm{~cm}^{-1}$ [16]. After vacuum heating, the $\mathrm{O}-\mathrm{H}$ band of the stretching vibration and the $\mathrm{C}-\mathrm{O}-\mathrm{C}$ band shift to $3441 \mathrm{~cm}^{-1}$ and $1096 \mathrm{~cm}^{-1}$, respectively, and the breadth and intensity fall dramatically. Moreover, the $\mathrm{C}=\mathrm{O}$ stretching vibration band also disappears.
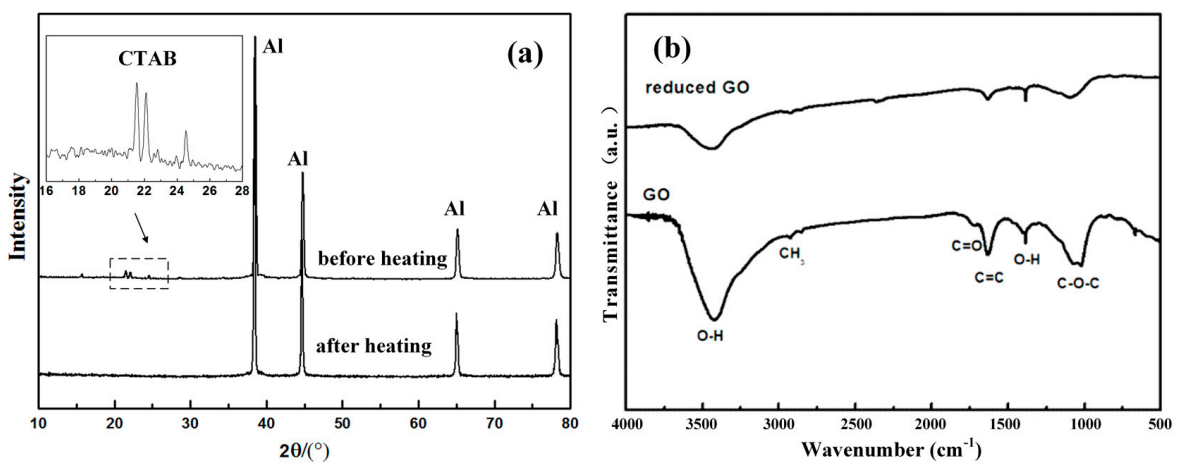

Figure 7. (a) XRD patterns for the composite powders before and after heating; and (b) FTIR spectra of GO and rGO after thermal reduction. 


\subsection{Microstructure}

The representative OM images for the ND-TD surface of $\mathrm{rGO} / 7075 \mathrm{Al}$ composites are shown in Figure 8. The microstructure shows a typical fibrous structure attributed to the hot extrusion. Due to this microstructure, it is very difficult to make a quantitative measurement on grain size. In order to determine the phase composition of the composites, the X-ray diffraction was performed. The XRD patterns for $7075 \mathrm{Al}$ and $\mathrm{rGO} / 7075 \mathrm{Al}$ composites are given in Figure 9. According to the $\mathrm{XRD}$ results, major aluminum peaks are observed at $38.47^{\circ}(111), 44.71^{\circ}(200), 65.09^{\circ}(220)$, and $78.22^{\circ}$ (3 1 1) (PDF\#65-2869). A MgZn 2 (2 0 0) peak at 40.17 (PDF\#65-3578) and an AlCu (-7 12$)$ peak at $58.11^{\circ}$ (PDF\#26-0016) are also observed. These second phases in the aluminum matrix were mainly precipitated in the process of aging treatment and benefitted to improve the mechanical properties of $7075 \mathrm{Al}$ alloys through precipitation strengthening mechanism [23]. Based on the XRD patterns and Scherrer's equation [24], the average crystal size of $7075 \mathrm{Al}, 0.15,0.30$, and $0.50 \mathrm{wt} \% \mathrm{rGO} / 7075 \mathrm{Al}$ composites are $91.3 \mathrm{~nm}, 64.7 \mathrm{~nm}, 51.3 \mathrm{~nm}$ and $46.0 \mathrm{~nm}$ respectively. No aluminum carbide $\left(\mathrm{Al}_{4} \mathrm{C}_{3}\right)$ peak or graphene peak is found in the XRD patterns, different from the detection results obtained by Rashad et al. [15] and Li et al. [25]. However, it cannot be concluded that no $\mathrm{Al}_{4} \mathrm{C}_{3}$ phase was formed during the sintering process, since the rGO content (up to $0.5 \mathrm{wt} \%$ ) is probably beyond the detection limit of XRD. As the interfacial phase $\left(\mathrm{Al}_{4} \mathrm{C}_{3}\right)$ and the bonding condition between $\mathrm{rGO}$ and matrix are very significant to the mechanical properties of composites, it is necessary to analyze the $\mathrm{rGO} / 7075 \mathrm{Al}$ composites by TEM.

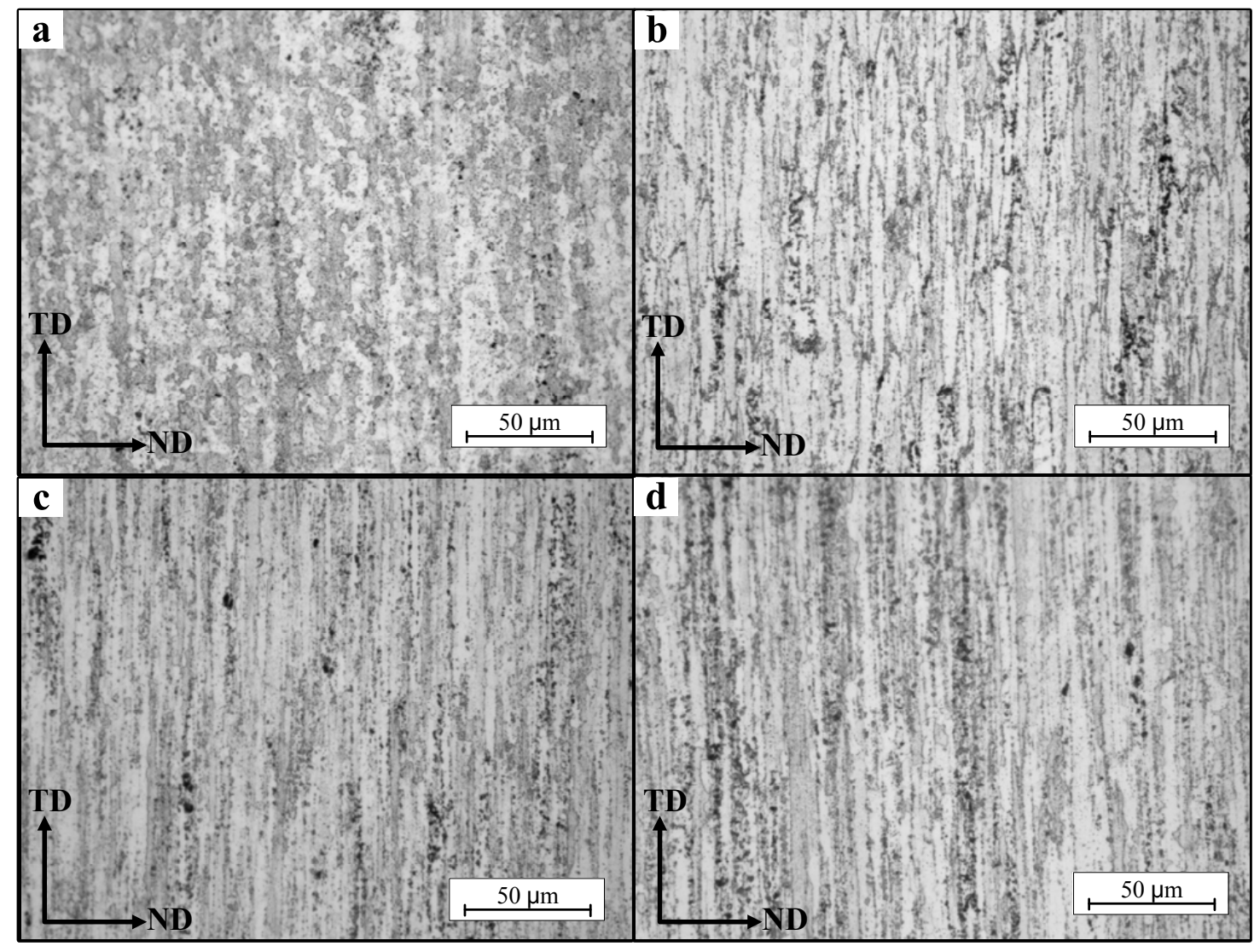

Figure 8. OM images of ND-TD surface for (a) $7075 \mathrm{Al}$; (b) 0.15 wt \% rGO/7075 Al; (c) 0.30 wt \% $\mathrm{rGO} / 7075$; and (d) $0.50 \mathrm{wt} \% \mathrm{rGO} / 7075$. 


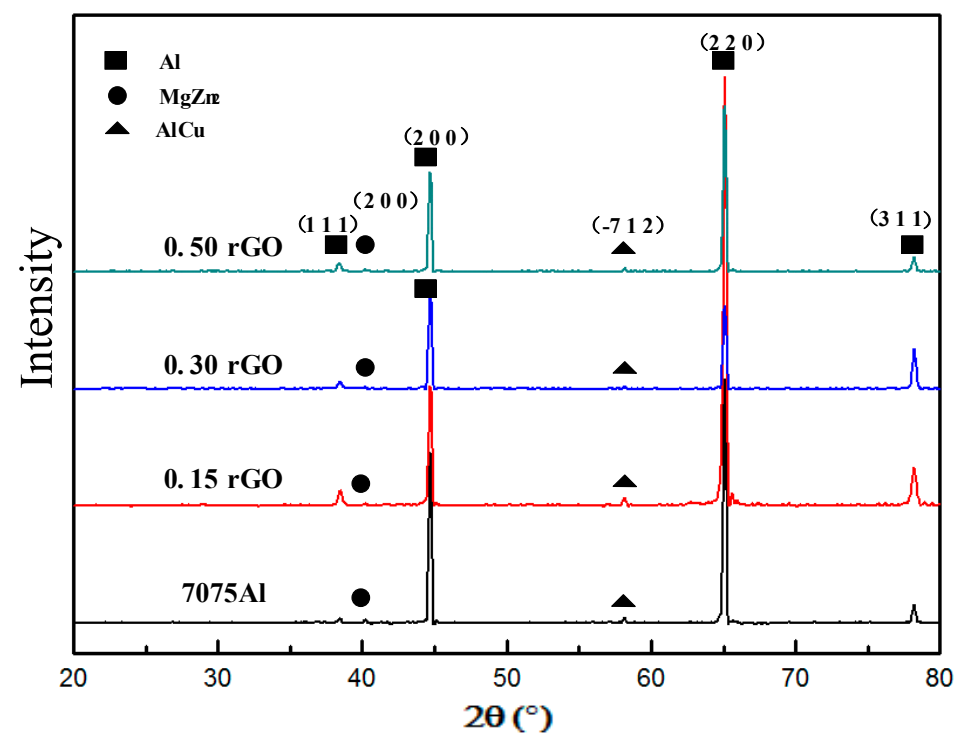

Figure 9. XRD patterns for $7075 \mathrm{Al}$ alloys without and with different contents of rGO addition.

TEM morphology of the $0.30 \mathrm{rGO} / 7075 \mathrm{Al}$ composite is shown in Figure 10 . As shown by the white arrows, several wrinkled edges are observed as a typical feature of rGO, indicating that the rGO was not destroyed by thermal reduction. It can also be concluded that a good exfoliation of GO occurred through sonication. For the bonding condition, rGO is closely embedded in the Al grain boundary free from defects, porosity, or impurities. Although no $\mathrm{Al}_{4} \mathrm{C}_{3}$ phase is detected via $\mathrm{X}$-ray diffraction (Figure 9), some black interfacial products (as shown by white arrows) are found at the interface. These products are further identified as $\mathrm{Al}_{4} \mathrm{C}_{3}$ phase via selected area electron diffraction (SAED) analysis, which is in agreement with the result obtained by Li et al. [25]. The TEM result reveals that the disappearance of $\mathrm{Al}_{4} \mathrm{C}_{3}$ phase in XRD patterns is due to the detection limit of the $\mathrm{X}$-ray diffraction equipment.

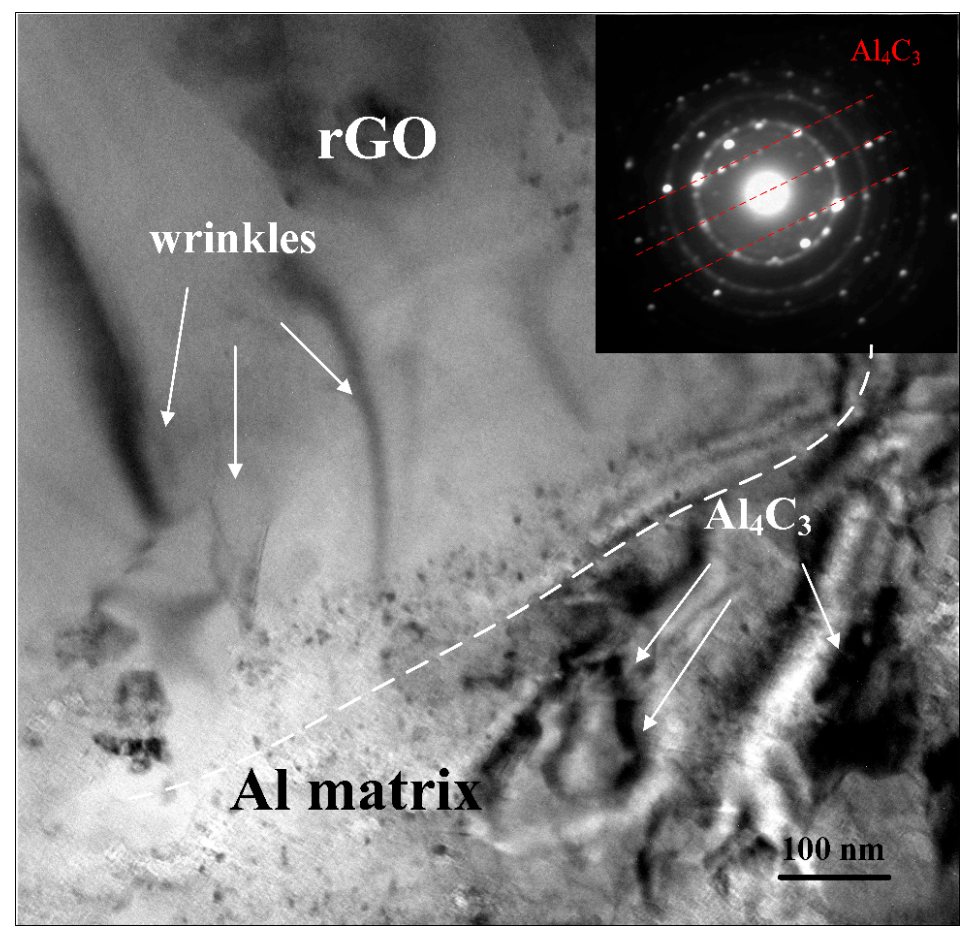

Figure 10. TEM image of $0.30 \mathrm{rGO} / 7075 \mathrm{Al}$ composite. 


\subsection{Mechanical Properties}

The Vickers hardness results of $7075 \mathrm{Al}$ and composites are presented in Figure 11a. As shown in Figure 11a, the Vickers hardness value increases with the increasing rGO content. This improvement is attributed to the uniformly distributed rGO provided to transfer load from the $7075 \mathrm{Al}$ matrix and restrains the dislocation movement during indentations. On the other hand, the density of composites also plays a vital role in affecting their hardness. Table 2 shows the density and the relative density of $7075 \mathrm{Al}$ and composites. All composites display a high relative density at $\sim 99.40 \%$, though with rGO addition the relative density of composites slightly decreases. This phenomenon indicates that an outstanding densification is achieved through sintering and extrusion. Compared to the density, the reinforcement rGO plays a more important role in improving the hardness.
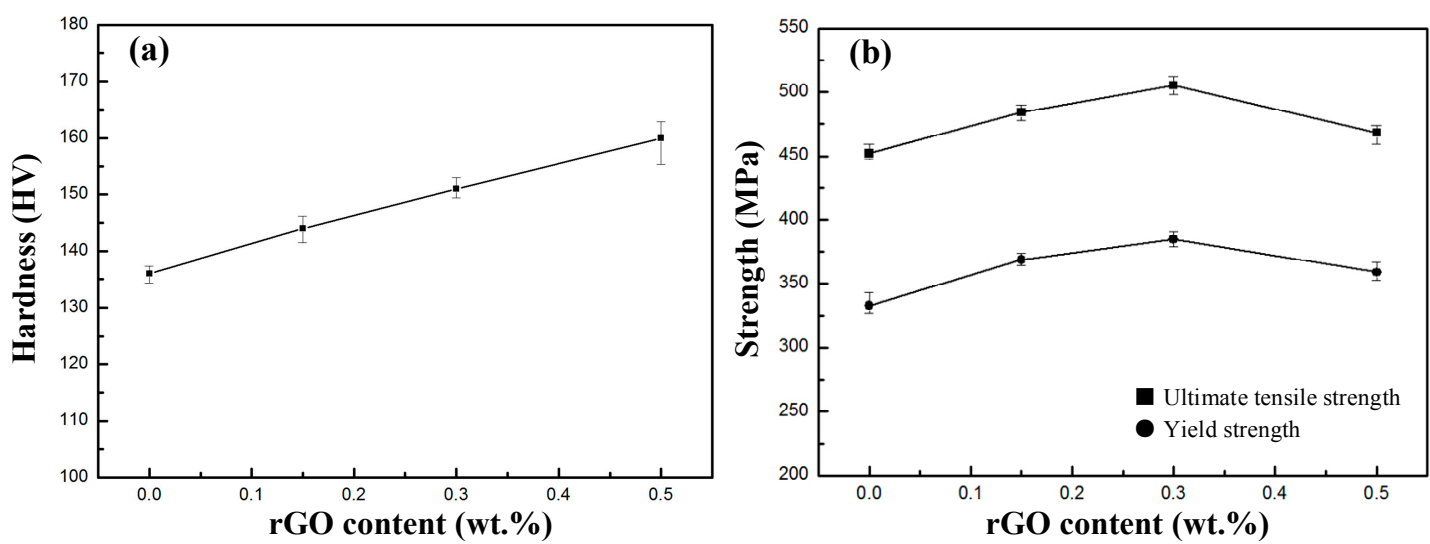

Figure 11. The variation tendencies of (a) hardness and (b) yield strength, and the ultimate tensile strength with rGO content.

Table 2. Densities of $7075 \mathrm{Al}$ and $\mathrm{rGO} / 7075 \mathrm{Al}$.

\begin{tabular}{cccc}
\hline Materials & Density $\left(\mathbf{g} \cdot \mathbf{c m}^{-3}\right)$ & Theoretical Density $\left(\mathbf{g} \cdot \mathbf{c m}^{-3}\right)$ & Relative Density $\mathbf{( \% )}$ \\
\hline $7075 \mathrm{Al}$ & 2.7863 & 2.8000 & 99.51 \\
$0.15 \mathrm{rGO} / 7075 \mathrm{Al}$ & 2.7830 & 2.7989 & 99.43 \\
$0.30 \mathrm{rGO} / 7075 \mathrm{Al}$ & 2.7823 & 2.7979 & 99.44 \\
$0.50 \mathrm{rGO} / 7075 \mathrm{Al}$ & 2.7795 & 2.7966 & 99.39 \\
\hline
\end{tabular}

The tensile properties of composites with different addition contents of rGO are presented in Table 3. As shown in Table 3, rGO exhibits a significant effect on the tensile properties of $7075 \mathrm{Al}$ alloys. Compared with $7075 \mathrm{Al}$ having $452 \mathrm{MPa}$ tensile strength, $333 \mathrm{MPa}$ yield strength, the composites all show higher tensile properties. Figure $11 \mathrm{~b}$ displays the variation tendencies of yield strength and ultimate tensile strength with increasing rGO content. The yield strength and the ultimate tensile strength both display an increase followed by a decrease, and reach the peak value at $385 \mathrm{MPa}$ and $505 \mathrm{MPa}$, respectively, with $0.30 \mathrm{wt} \% \mathrm{rGO}$ addition. Compared with $7075 \mathrm{Al}$, the yield strength and ultimate tensile strength are increased by $15.6 \%$ and $11.7 \%$. For the elongation, the composites experience a decrease in elongation with rGO content increasing.

Table 3. Tensile properties of $7075 \mathrm{Al}$ and $\mathrm{rGO} / 7075 \mathrm{Al}$ composites.

\begin{tabular}{clll}
\hline Materials & Yield Strength (MPa) & UTS (MPa) & Elongation \\
\hline $7075 \mathrm{Al}$ & $333_{-3}^{+5}$ & $452_{-5}^{+7}$ & $13.5_{-0.7}^{+0.5}$ \\
$0.15 \mathrm{rGO} / 7075 \mathrm{Al}$ & $369_{-1}^{+1}$ & $484_{-2}^{+2}$ & $11.8_{-0.2}^{+0.2}$ \\
$0.30 \mathrm{rGO} / 7075 \mathrm{Al}$ & $385_{-2}^{+2}$ & $505_{-3}^{+3}$ & $10.7_{-0.7}^{+0.5}$ \\
$0.50 \mathrm{rGO} / 7075 \mathrm{Al}$ & $359_{-3}^{+4}$ & $468_{-9}^{+6}$ & $8.0_{-0.8}^{+0.4}$ \\
\hline
\end{tabular}




\section{Discussion}

The significant difference in the dispersion uniformity of GO between the unmodified $7075 \mathrm{Al}$ powder and the CTAB-modified $7075 \mathrm{Al}$ powder reveals the critical effect of CTAB modification on improving the absorption uniformity of GO. The FTIR spectrum for GO (Figure 7b) reveals that GO is fabricated with large amounts of hydrophilic oxygen-containing groups, such as $-\mathrm{OH},-\mathrm{COOH}$, and $-\mathrm{C}=\mathrm{O}$, endowing the $\mathrm{GO}$ with hydrophilic surface property, are very similar to the $-\mathrm{COOH}$ functionalized carbon nanotubes [26]. However, due to the naturally-formed alumina film, $7075 \mathrm{Al}$ powder is identified as hydrophobic [26]. The contradictory water wettability determines that the GO can hardly form a homogeneous distribution with the unmodified $7075 \mathrm{Al}$ powders through stirring.

CTAB is a water soluble cationic surfactant that shows good coordination with anionic and amphoteric surfactants [27]. The FTIR spectrum for CTAB-modified 7075 Al powder (Figure 4) reveals that a considerable number of positive charges $\left(\mathrm{CTA}^{+}\right)$were introduced on the surface of $7075 \mathrm{Al}$ powder. The CTAB modification leads to the formation of a thin cationic membrane due to its hydrophobic long carbon chains and electropositive polar groups. The compatible water wettability of alumina film plays a key role in absorbing the long carbon chains through van der Waals force to form a stable CTAB membrane [18]. The CTAB membrane also introduces a large number of positive charges onto the surface of the $7075 \mathrm{Al}$ powder. Due to the negative charged nature, GO tends to absorb onto the cationic CTAB membrane through electrostatic attraction and, thus, a uniform distribution of GO in the CTAB-modified $7075 \mathrm{Al}$ powders can be effectively achieved.

To achieve the removal of impurity (CTAB in this research) and the reduction of GO, Wang et al. [16] and Jiang et al. [26] employed the extra thermal treatment. However, the TGA result for CTAB (Figure 6a) shows a remarkable mass loss $(\sim 90 \%)$ up to $560{ }^{\circ} \mathrm{C}$, indicating a complete decomposition of $\mathrm{CTAB}$ during the sintering process, which can also be proven by the XRD patterns for the composite powders before and after heating (Figure 7a). Meanwhile, the TGA result for $\mathrm{GO}$ up to $560{ }^{\circ} \mathrm{C}$ (Figure $6 \mathrm{~b}$ ) displays the mass loss in three discrete stages. In accordance with the analysis obtained by Tegou et al. [28], the mass loss ( 10\%) in the first stage is mainly caused by the elimination of physisorbed and interlamellar water molecules. The significant mass loss $(\sim 32 \%)$ in the second stage is primarily attributed to the thermal decomposition of covalently bonded oxygen. Finally, in the last stage the mass loss $(\sim 8 \%)$ is caused by the removal of more stable oxygen-containing functional groups. However, compared to the TGA results obtained by Tegou et al. [28], the $150{ }^{\circ} \mathrm{C}$ decomposition temperature here is approximately $30^{\circ} \mathrm{C}$ higher, while the ending temperature of the second stage is $260{ }^{\circ} \mathrm{C}, 60^{\circ} \mathrm{C}$ higher. The difference is probably due to the ambient atmosphere adopted in literature [28], while the TGA in this investigation was carried out in vacuum atmosphere. The FTIR spectrum (Figure $7 \mathrm{~b}$ ) also demonstrate the disappearance of the oxygen functional groups on GO, suggesting the thermal reduction of GO into rGO during the sintering period.

The strengthening mechanisms of well dispersed $\mathrm{rGO}$ reinforcing $\mathrm{rGO} / 7075 \mathrm{Al}$ composites are generally explained by grain refinement, stress transfer, and dislocation strengthening: as a nano-reinforcement, rGO is expected to impede the grain coarsening during thermal processing, resulting in higher mechanical properties [16]. Although the results of XRD spectra shows that the average crystal size decreases with rGO content increasing, the OM images of $\mathrm{rGO} / 7075 \mathrm{Al}$ composites and $7075 \mathrm{Al}$ show little difference in grain size. According to the investigation of Li et al. [25], the effect of grain refinement is negligible due to the hot-pressed sintering, which employs a low temperature avoiding $7075 \mathrm{Al}$ changing into a liquid state. The enhancement of strength for composites is strongly depended on the interfacial bonding between $\mathrm{rGO}$ and matrix. TEM results show a good interfacial bonding condition obtained in this study. A good interfacial bonding condition allows the tensile stress to transfer from matrix to reinforcements and create an interfacial shear stress [29]. The contribution of yield strength increase for composites can be calculated from shear lag model [15]:

$$
\sigma_{S L}=\sigma_{m}+f_{v} \sigma_{m}\left(\frac{S}{2}\right)
$$


where $\sigma_{S L}$ is yield strength of composite calculated by shear stress model, $f_{v}$ is volume fraction of $\mathrm{rGO}, \sigma_{m}$ is yield strength of $\mathrm{Al}$ matrix, and $\mathrm{S}$ is aspect ratio of rGO. The wrinkles on the rGO surface were also reported to be beneficial to the formation of the mechanical bond between $\mathrm{rGO}$ and the pure Al matrix [30].

Orowan looping is an important model related to dislocation strengthening. The addition of rGO contributes to the strengthening through restricting dislocation movements. A uniform dispersion of rGO could offer a large number of nano-particles to take part in this strengthening mechanism [25]. Plastic deformation leads to form residual dislocation loops around $\mathrm{rGO}$ and these loops produce back stress restricting dislocation movement and, thus, increasing the strength [15]. On the other hand, the significant mismatch in coefficient of thermal expansion (CTE) between rGO and the $7075 \mathrm{Al}$ matrix $\left(\mathrm{CTE}_{r G O}=0.9 \times 10^{-6} \mathrm{~K}^{-1}, \mathrm{CTE}_{7075} \mathrm{Al}=23.6 \times 10^{-6} \mathrm{~K}^{-1}\right)$ can form a large number of dislocations at the interface. Dislocation density is determined by the surface area of reinforcement. Smaller reinforcement particles lead to a higher dislocation density which results in the strengthening of the composites [31]. Due to its unique two-dimensional structure, rGO is known for its very large surface area (theoretically as much as $2630 \mathrm{~m}^{2} / \mathrm{g}$ ) [32]. Therefore, rGO is able to contribute to a rather high dislocation density. The yield strength of composites $\sigma_{c}$ can be calculated by the following equation [33]:

$$
\sigma_{c}=\left(1+0.5 f_{v}\right)\left(\sigma_{m}+\Delta \sigma_{C T E}+\Delta \sigma_{O}+\frac{\Delta \sigma_{O} \Delta \sigma_{C T E}}{\sigma_{m}}\right)
$$

where:

$$
\begin{gathered}
\Delta \sigma_{O}=\frac{0.13 G b}{d_{p}\left[\left(\frac{1}{2 f_{v}}\right)^{\frac{1}{3}}-1\right]} \ln \left(\frac{d_{p}}{2 b}\right) \\
\Delta \sigma_{C T E}=1.25 G b \sqrt{\frac{12 \Delta \mathrm{T} \Delta \mathrm{C} f_{v}}{b d_{p}}}
\end{gathered}
$$

where $\mathrm{G}$ is the shear modulus of the $7075 \mathrm{Al}$ matrix, $\mathrm{b}$ is the Burgers vector of matrix $(0.286 \mathrm{~nm}$ for $7075 \mathrm{Al}), \Delta \mathrm{T}$ is the difference between the processing temperature and the testing temperature, $\Delta \mathrm{C}$ is the difference in CTE between the matrix and $\mathrm{rGO}, f_{v}$ is the volume fraction of $\mathrm{rGO}$, and $d_{p}$ is the mean particle size of rGO.

Figure 12 displays the comparison of yield strength obtained from different models and the present study. The experimental data matches closely with the theoretical prediction by the Orowan strengthening mechanism, indicating that the Orowan strengthening mechanism is predominant in the $\mathrm{rGO} / 7075 \mathrm{Al}$ composites. Uniform dispersion of $\mathrm{rGO}$ in the matrix restricts the dislocation motion in the matrix and leads to high dislocation density at the $\mathrm{rGO} / 7075 \mathrm{Al}$ interface [31]. Higher surface area and smaller particle size of rGO will lead to higher dislocation density.

However, it is worth noting that the excessive addition of $\mathrm{rGO}(0.50 \mathrm{wt} \%)$ gives rise to a weakening in the enhancement of the tensile properties compared with $0.30 \mathrm{rGO} / \mathrm{Al}$ composite, which is different from the prediction by Orowan strengthening mechanism. The decrease in tensile properties might be caused by the formation of $\mathrm{Al}_{4} \mathrm{C}_{3}$ in the composites, an interfacial product between the $\mathrm{rGO}$ and $\mathrm{Al}$ matrix formed at high sintering temperature via the following reaction:

$$
4 \mathrm{Al}_{(s)}+3 \mathrm{C}_{(s)} \rightarrow \mathrm{Al}_{4} \mathrm{C}_{3}
$$

Moreover, Koratkar et al. [17] reported that wrinkles and folds on the surface of rGO provide massive defect sites, which could become reaction sites for the $\mathrm{Al}_{4} \mathrm{C}_{3}$ formation. $\mathrm{Al}_{4} \mathrm{C}_{3}$ is known as a brittle phase having harmful effects on tensile properties of composites [25]. Thus, the increasing amount of $\mathrm{Al}_{4} \mathrm{C}_{3}$ is likely to be the primary factor leading to the weakening in the enhancement of tensile properties for $0.50 \mathrm{rGO} / 7075 \mathrm{Al}$.

The fracture morphology of $7075 \mathrm{Al}$ and composites is presented in Figure 13. A large number of dimples and transgranular fracture surfaces are observed in $7075 \mathrm{Al}$ and all composites, indicating the 
ductile failure. For the composites with different contents of rGO addition, the pull-out rGO is found at the edge of dimples. Meanwhile the amount of dimples decreases with increasing rGO content, leading to the decrease in elongation. Apart from the pull-out rGO, cracks are detected on the fracture surface of $0.30 \mathrm{rGO} / 7075 \mathrm{Al}$ and $0.50 \mathrm{rGO} / 7075 \mathrm{Al}$, and the number of cracks increases with increasing rGO content from 0.30 to $0.50 \mathrm{wt} \%$. At the edge of the cracks, some pull-out rGO is also observed. This phenomenon might result from the weak bonding force of the few-layered rGO used in this study (see AFM in Figure 2). The cracks are most likely to originate at the interlayer of rGO and propagate along the tensile direction [18]. Therefore, the increasing rGO content also leads to an increase in cracks, having a negative effect on the tensile properties and elongation. When the rGO content reaches a critical value, the negative effect of cracks becomes predominant and causes the tensile properties of composites to decline. It is anticipated, with further increasing rGO content (larger than $0.50 \mathrm{wt} \%$ ), that the excess rGO will give rise to a lower tensile strength even in comparison to $7075 \mathrm{Al}$.

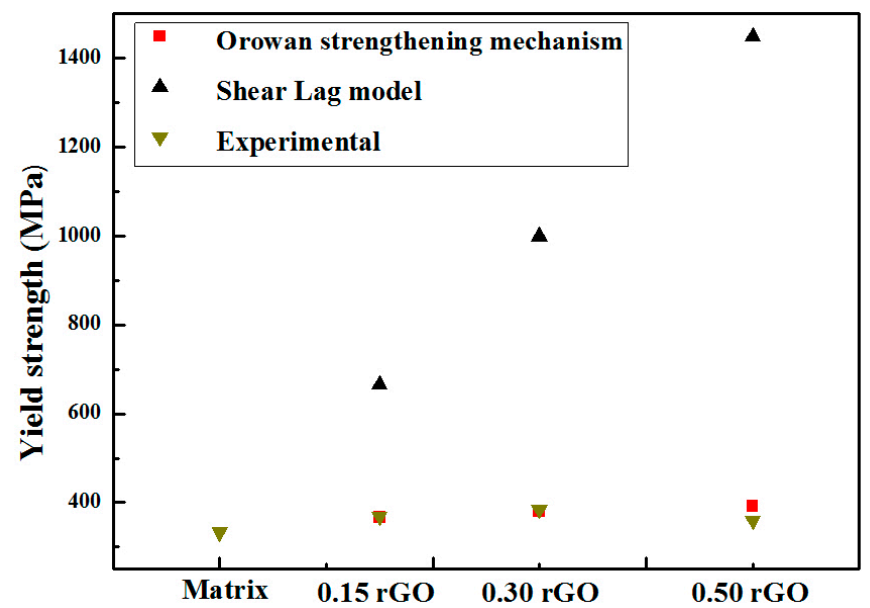

Figure 12. Comparison of yield strength calculated by different models and experimental data.
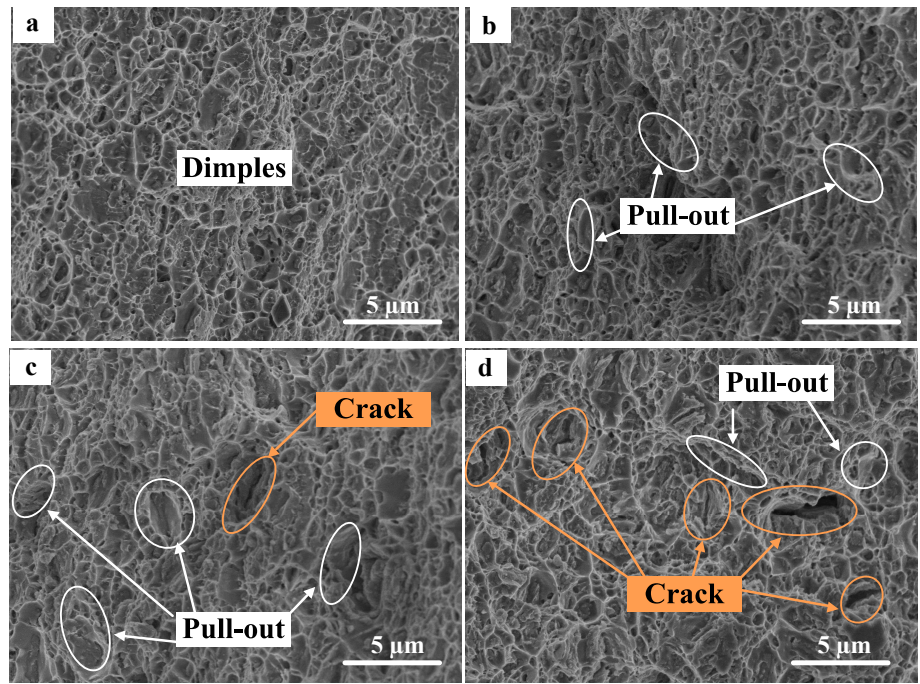

Figure 13. Tensile fracture morphologies of (a) $7075 \mathrm{Al}$; (b) $0.15 \mathrm{rGO} / 7075 \mathrm{Al}$; (c) $0.30 \mathrm{rGO} / 7075 \mathrm{Al}$; and (d) $0.50 \mathrm{rGO} / 7075 \mathrm{Al}$.

\section{Conclusions}

We have fabricated $7075 \mathrm{Al}$ matrix nanocomposites based on powder metallurgy and electrostatic self-assembly processes. The effect of rGO content on the mechanical properties of rGO/7075 Al composites were studied. The results are summarized as follows: 
(1) The significant improvement in the adsorption uniformity of GO is attributed to the formation of the cationic CTAB membrane on $7075 \mathrm{Al}$ powders. Due to the negatively-charged nature, GO tends to absorb onto the cationic CTAB membrane through electrostatic attraction and, thus, a uniform distribution of GO in the CTAB-modified $7075 \mathrm{Al}$ powders is effectively achieved.

(2) During the sintering process, CTAB is effectively removed before $350{ }^{\circ} \mathrm{C}$ so that it would have little negative effect on the mechanical properties of composites. On the other hand, the thermal reduction of GO is demonstrated by the results of TGA and FTIR.

(3) The Vickers hardness of $\mathrm{rGO} / 7075 \mathrm{Al}$ composites increases with the increase in rGO content. rGO has a significant effect on the tensile properties of $7075 \mathrm{Al}$ alloys. Compared with $7075 \mathrm{Al}$, the composites all show higher tensile properties. The yield strength and the ultimate tensile strength both reach the peak values for $\mathrm{rGO} / 7075 \mathrm{Al}$ composite with $0.30 \mathrm{wt} \% \mathrm{rGO}$ addition. The yield strength and ultimate tensile strength of $0.30 \mathrm{rGO} / 7075 \mathrm{Al}$ are increased by $15.6 \%$ and $11.7 \%$ compared with $7075 \mathrm{Al}$. The improvement in strength of $\mathrm{rGO} / 7075 \mathrm{Al}$ composites is attributed to stress transfer and dislocation strengthening. With rGO content reaching $0.50 \mathrm{wt} \%$, however, the excessive addition of rGO gives rise to a weakening in the enhancement of the tensile properties compared with $0.30 \mathrm{rGO} / \mathrm{Al}$ composite, due to the increasing amounts of brittle $\mathrm{Al}_{4} \mathrm{C}_{3}$ and cracks.

Acknowledgments: Financial supports from SinoProbe-09-05 (project No. 201011082) and International S\&T Cooperation Program of China (grant No. 2013DFR70490).

Author Contributions: Youhong Sun, Chi Zhang, and Baochang Liu conceived and designed the experiments; Chi Zhang and Wenhao Dai performed the experiments; Shaoming Ma and Qingnan Meng analyzed the data; Chi Zhang, Qingnan Meng, and Wenhao Dai contributed reagents, materials, and analysis tools; and Chi Zhang wrote the paper.

Conflicts of Interest: The authors declare no conflict of interest

\section{References}

1. Miracle, D.B. Metal matrix composites-from science to technological significance. Compos. Sci. Technol. 2005, 65, 2526-2540.

2. Surappa, M.K. Aluminum matrix composites: Challenges and opportunities. Sadhana 2003, 28, 319-334.

3. Williams, J.C.; Strake, E.A., Jr. Process in structural materials for aerospace systems. Acta Mater. 2003, 51, 5775-5799.

4. Li, B.; Pan, Q.L.; Chen, C.P.; Wu, H.H.; Yin, Z.M. Effects of solution treatment on microstructural and mechanical properties of Al-Zn-Mg alloy by microalloying with Sc and Zr. J. Alloys Compd. 2016, 664, 553-564.

5. Davydov, V.G.; Rostova, T.D.; Zakharov, V.V.; Filatov, Y.A.; Yelagin, V.I. Scientific principles of making an alloying addition of scandium to aluminum alloys. Mater. Sci. Eng. A 2000, 280, 30-36.

6. Jones, M.J.; Humphreys, F.J. Interaction of recrystallization and precipitation: The effect of Al3Sc on the recrystallization behavior of deformed aluminum. Acta Mater. 2003, 51, 2149-2159.

7. Shen, Q.; Wu, C.D.; Luo, G.Q.; Fang, P.; Li, C.Z.; Wang, Y.Y.; Zhang, L.M. Microstructure and mechanical properties of Al-7075/B4C composites fabricated by plasma activated sintering. J. Alloys Compd. 2014, 588, 265-270.

8. Panigrahi, S.K.; Jayaganthan, R. Effect of ageing on microstructure and mechanical properties of bulk, cryorolled, and room temperature rolled Al 7075 alloy. J. Alloys Compd. 2011, 509, 9609-9616.

9. Taleghani, M.A.J.; Ruiz Navas, E.M.; Torralba, J.M. Microstructural and mechanical characterization of 7075 aluminium alloy consolidated from a premixed powder by cold compaction and hot extrusion. Mater. Des. 2014, 55, 674-682.

10. Seiner, H.; Ramirez, C.; Koller, M.; Sedlak, P.; Landa, M.; Miranzo, P.; Belmonte, M.; Osendi, M.I. Elastic properties of silicon nitride ceramics reinforced with graphene nanofillers. Mater. Des. 2015, 87, 675-680.

11. Wang, H.D.; Kurata, K.; Fukunaga, T.; Zhang, X.; Takamatsu, H. Width dependent intrinsic thermal conductivity of suspended monolayer graphene. Int. J. Heat Mass Transf. 2017, 105, 76-80. 
12. Bolotin, K.I.; Sikes, K.J.; Jiang, Z.; Klima, M.; Fudenberg, G.; Hone, J.; Kim, P.; Stormer, H.L. Ultrahigh electron mobility in suspended graphene. Solid State Commun. 2008, 146, 351-355.

13. Geim, A.K.; Novoselov, K.S. The rise of graphene. Nat. Mater. 2007, 6, 183-191. [PubMed]

14. Begum, K.R.; Sankeshwar, N.S. Electronic thermal conduction in suspended graphene. Phys. E Low-Dimens. Syst. Nanostruct. 2015, 73, 27-34.

15. Rashad, M.; Pan, F.S.; Tang, A.T.; Asif, M. Effect of Graphene Nanoplatelets addition on mechanical properties of pure aluminum using a semi-powder method. Prog. Nat. Sci. Mater. Int. 2014, 24, 101-108.

16. Wang, J.Y.; Li, Z.Q.; Fan, G.L.; Pan, H.H.; Chen, Z.X.; Zhang, D. Reinforcement with graphene nanosheets in aluminum matrix composites. Scr. Mater. 2012, 66, 594-597.

17. Bartolucci, S.F.; Paras, J.; Rafiee, M.A.; Rafiee, J.; Lee, S.; Kapoor, D.; Koratkar, N. Graphene-aluminum nanocomposites. Mater. Sci. Eng. A 2011, 528, 7933-7937.

18. Gao, X.; Yue, H.Y.; Guo, E.J.; Zhang, H.; Lin, X.Y.; Yao, L.H.; Wang, B. Preparation and tensile properties of homogeneously dispersed graphene reinforced aluminum matrix composites. Mater. Des. 2016, 94, 54-60.

19. De Silva, K.K.H.; Huang, H.H.; Joshi, R.K.; Yoshimura, M. Chemical reduction of graphene oxide using green reductants. Carbon 2017, 119, 190-199.

20. ASTM Standard E8/E8M, 2009. Standard Test Methods for Tension Testing of Metallic Materials; ASTM International: Montgomery County, PA, USA, 2009. [CrossRef]

21. Zhu, J.X.; He, H.P.; Zhu, L.Z.; Wen, X.Y.; Deng, F. Characterization of organic phases in the interlayer of montmorillonite using FTIR and ${ }^{13}$ C NMR. J. Colloid Interface Sci. 2005, 286, 239-244. [PubMed]

22. Yu, W.H.; Ren, Q.Q.; Tong, D.S.; Zhou, C.H.; Wang, H. Clean production of CATB-montmorillonite: Formation mechanism and swelling behavior in xylene. Appl. Clay Sci. 2014, 97-98, 222-234.

23. Han, N.M.; Zhang, X.M.; Liu, S.D.; He, D.G.; Zhang, R. Effect of solution treatment on the strength and fracture toughness of aluminum alloy 7050. J. Alloys Compd. 2011, 509, 4138-4145.

24. Meng, Q.N.; Wen, M.; Mao, F.; Nedfors, N.; Jansson, U.; Zheng, W.T. Deposition and characterization of reactive magnetron sputtered zirconium carbide films. Surf. Technol. 2013, 232, 876-883.

25. Li, G.; Xiong, B.W. Effect of graphene content on microstructures and tensile property of graphene-nanosheets/aluminum composites. J. Alloys Compd. 2017, 697, 31-36.

26. Jiang, L.; Fan, G.L.; Li, Z.Q.; Kai, X.Z.; Zhang, D.; Chen, Z.X.; Humphries, S.; Heness, G.; Yeung, W.Y. An approach to the uniform dispersion of a high volume fraction of carbon nanotubes in aluminum powder. Carbon 2011, 49, 1968-1971.

27. Yang, Y.J.; Li, W.K. CTAB functionalized graphene oxide/multiwalled carbon nanotube composite modified electrode for the simultaneous determination of ascorbic acid, dopamine, uric acid and nitrite. Biosens. Bioelectron. 2014, 56, 300-306. [PubMed]

28. Tegou, E.; Pseiropoulos, G.; Filippidou, M.K.; Chatzandroulis, S. Low-temperature thermal reduction of graphene oxide films in ambient aptmosphere: Infra-red spectroscopic studies and gas sensing applications. Microelectron. Eng. 2016, 159, 146-150.

29. Dixit, S.; Mahata, A.; Mahapatra, D.R.; Kailas, S.V.; Chattopadhyay, K. Multi-layer graphene reinforced aluminum-Manufacturing of high strength composite by friction stir alloying. Compos. Part B Eng. 2018, $136,63-71$.

30. Bisht, A.; Srivastava, M.; Kumar, R.M.; Lahiri, I.; Lahiri, D. Strengthening mechanism in graphene nanoplatelets reinforced aluminum composite fabricated through spark plasma sintering. Mater. Sci. Eng. A 2017, 695, 20-28.

31. Arsenault, R.J.; Shi, N. Dislocation generation due to differences between the coefficients of thermal expansion. Mater. Sci. Eng. 1986, 81, 175-187.

32. Yin, C.M.; Wang, J.F. Effects of activation temperature on the deoxygenation specific surface area and supercapacitor performance of graphene. Carbon 2016, 109, 558-565. [CrossRef]

33. Zhang, Z.; Chen, D.L. Consideration of Orowan strengthening effect in particulate-reinforced metal matrix nanocomposites: A model for predicting their yield strength. Scr. Mater. 2006, 54, 1321-1326. [CrossRef]

(C) 2017 by the authors. Licensee MDPI, Basel, Switzerland. This article is an open access article distributed under the terms and conditions of the Creative Commons Attribution (CC BY) license (http:/ / creativecommons.org/licenses/by/4.0/). 